\title{
MUCOPOLYSACCHARIDOSIS TYPE VI (MAROTEAUX-LAMY SYNDROME) - A CASE IN PERU
}

\author{
Jenny Cortez Miranda ${ }^{1}$, Lincoln Blacido Trujillo ${ }^{1}$, and Maria Liendo Chocano ${ }^{1}$ \\ ${ }^{1}$ Hospital Militar Central
}

May 6, 2020

\begin{abstract}
A patient with mucopolysaccharidosis type VI, on enzyme replacement therapy (galsulfase) for more than 6-years with good adherence. Urine glycosaminoglycans became stable, cardiopulmonary progression is slow, motor skills have improved, pain is controlled and no adverse reactions were reported. These support the benefits of galsulfase, as it slows disease progression.
\end{abstract}

\section{Key Clinical Message}

A patient on enzyme replacement therapy (galsulfase) for more than 6-years. Supporting the long-term benefits of galsulfase as an option to modify the natural history and the quality of life in patients with Mucopolysaccharidosis VI.

\section{INTRODUCTION}

Mucopolysaccharidosis type VI (MPS VI, Maroteaux-Lamy syndrome) is an autosomal recessive lysosomal storage disorder caused by a deficiency of the N-acetylgalactosamine 4 sulfatase enzyme (also known as arylsulfatase B or ASB) which results in the accumulation of the glycosaminoglycan (GAG) dermatan sulfate (DS) in different tissues. [1] The disease is associated with high morbidity and reduced life expectancy, [2,3] although its incidence is lower than that of other MPS (1 / 455,000 live births).[4] In Monte Santo, Brazil, the prevalence is estimated at 20/1,000,000, probably as a result of a founding effect and inbreeding, with a single homozygous mutation present (p.H178L) [5] No studies reporting the prevalence of this disease are available in Peru or other Latin American countries.

The $\mathrm{N}$-acetylgalactosamine 4 sulfatase enzyme is found predominantly in the skin, but also in tendons, blood vessels, airways and heart valves.[6] Studies have shown that DS accumulation creates an inflammatory response through the tumor necrosis factor (TNF) pathway, resulting in chondrocyte apoptosis and ensuing progressive arthropathy, $[7,8]$ affecting bone, cartilage, liver, spleen, ligaments, joints, heart valves, airways, meninges and corneas.

Clinical signs and symptoms are multisystemic and heterogenous as a result of DS accumulation in the different tissues. There is evidence of growth stunting, coarse facies, thick hair, skeletal deformities, frequent upper airway infections, hepatosplenomegaly, hearing loss, sleep apnea and stiff joints.[2] Also reported are other anatomical abnormalities and heart valve dysfunction in all patients. [3]

Patients with MPS VI generally appear healthy at birth, with symptoms usually manifesting in early infancy as a result of increased GAG concentration in the cells. The clinical presentation varies according to the age of onset and the rate of progression of the disease. Progression of MPS VI is categorized as classical 
or atypical, depending on the symptoms. [9 ] The highest urinary GAG levels are associated with rapidly progressing disease. [9]

$A S B$ mutations have a genotype-phenotype correlation according to residual enzyme activity and are responsible for the heterogeneity of the clinical presentation. [10] The definitive diagnosis is made on the basis of deficient ASB enzyme activity confirmed in cultured fibroblasts or isolated leukocytes (value $<10 \%$ the lower limit of normal) and/or demonstration of two mutations that cause the disease. [2,3,11] Elevated GAGs in the urine and high DS concentrations are markers of disease activity but, alone, are not diagnostic methods.

Patients with MPS VI require an interdisciplinary approach to the management of their disease. Enzyme replacement therapy (ERT) with galsulfase was approved in 2005-2006 in Europe, the United States, Brazil, Ecuador and Australia, among other countries. [12,13] This therapy slows down disease progression as it restores ASB enzymatic function, preventing GAG accumulation. [14] It is associated with improved functional endurance tests (6-minute and 12-minute walk test, and 3-minute stair climb), reduction in urinary GAG levels, stabilization of cardiac and pulmonary progression at 5-year follow-up, and reduced 10-year mortality. [13,15-17]

The objective of this study is to report the case of a patient in Peru with a diagnosis of MPS VI on ERT, focusing on the general characteristics of MPS VI, the course of the disease, and findings regarding the use of enzyme replacement therapy over a 6 -year period.

\section{Case History / Examination}

A 9 years 10 months old male patient coming from northern Peru, born to a primigravida, with no relevant perinatal history, who exhibited normal psychomotor development up to 6 months of age. After that time, he developed evidence of discrete palpable and painless lumbar spine deformation together with increased head circumference, stunting and progressive joint stiffness affecting his ability to walk and grasp objects (1 year and 6 months of age) (Figure 1). Moreover, changes in features began to develop, with coarse facies, prominent forehead, thick hair, hirsutism, thick eyebrows, bulging eyes, broad nasal base, depressed nasal bridge, macroglossia, and small, spaced-out teeth. Persistent and worsening lumbar deformity added to joint stiffness prompted referral to a center specialized in physical medicine and rehabilitation where the patient was diagnosed with L2-L3 hemivertebrae and subjected to surgery for bilateral hip dysplasia.

\section{Investigations and treatment}

At 3 years of age, the patient was seen at the genetics service of the Child's Health Specialized Institute (Instituto Especializado de Salud del Niño ) where metabolic screening tests with cetyltrimethylammonium bromide and toluidine blue were positive for GAGs in the urine, and fluorometric quantification of $\mathrm{N}$-acetylgalactosamine 4 sulfatase in blood (carried out in Germany) showed a result of $20.8 \mu \mathrm{mol} / \mathrm{l} / \mathrm{h}$ (normal reference values $>50 \mu \mathrm{mol} / \mathrm{l} / \mathrm{h}$ ). $A S B$ sequencing (preformed at Centogene, Rostock, Germany) showed a homozygous deletion covering exons 7 and 8 , which was confirmed by qPCR and corroborates diagnosis of MPS VI.

Based on these findings, a deficiency of N-acetylgalactosamine 4 sulfatase (MPS VI) was diagnosed and the patient was referred to the Central Military Hospital for enzyme replacement treatment with galsulfase. The physical examination showed a patient 3 years and 6 months of age with global growth and developmental delay ( $\mathrm{z}$ score -0.88 for weight and -2.83 for height); head circumference greater than the 95th percentile; genu valgum associated with generalized joint stiffness and contractures; brachydactyly, claw hands, trigger finger, loss of fine motor skills; corneal opacity; small and spaced-out teeth; reducible umbilical hernia, and hepatomegaly (Figure 2).

Assessment by a multidisciplinary team found mild glaucoma, allergic rhinitis and bilateral otitis media; carpal syndrome-like bilateral median nerve neuropathy, predominantly of the left side; mild obstructive hypopnea; cranial hyperostosis; corrected acetabular dysplasia (history of surgically corrected coxa valga); vertebral narrowing with subluxation and kyphoscoliosis; hepatosplenomegaly; microcephaly with non-communicating hydrocephalus; and spinal cord compression at L1-L2 and C5-C6. 
Based on these findings, enzyme replacement therapy with galsulfase (N-acetylgalactosamine 4 sulfatase) 1 $\mathrm{mg} / \mathrm{kg} /$ week was initiated at 3 years 6 months of age. The patient was followed for 6 years and 4 months at the institution, with no evidence of drug-related adverse events.

\section{Outcome and follow-up}

Figure 3 illustrates weight, height and body mass index (BMI) during follow-up. During the follow-up period, the patient was diagnosed with levocardia in situs solitus and mild aortic, mitral and tricuspid regurgitation. Since the time of diagnosis, progression of the cardiac compromise has been stable and slow to this date. Additionally, the patient has shown improvement in speech, motor skills, snoring and physical endurance, enabling him to continue in school, with adequate socialization.

GAG measurements in urine are within the expected range in accordance with the type and course of the disease under treatment. Values have remained stable between 10.51 and $10.7 \mathrm{mg} \mathrm{GAG} / \mathrm{mmol} / \mathrm{cr}$, slightly elevated when compared to the normal population by age $(0.36-6.36 \mathrm{mg} \mathrm{GAG} / \mathrm{mmol} / \mathrm{cr})$.

No progression has been found in pulmonary function tests, or increase in hepatomegaly or splenomegaly during follow-up. The patient does not complain of joint pain, and reduction in generalized stiffness is evident. There is no evidence of metabolic abnormality, with glycemic and lipid profiles within normal limits. During follow-up, the patient has undergone trabeculectomy and bilateral intraocular valve insertion for glaucoma correction, and right lower lip hemangioma resection. Auditory evoked potentials performed at 9 years of age showed severe bilateral hearing loss. Evident difficulty with activities of daily living are due to the fact that the patient is a carrier of a severe and rapidly progressive variant of MPS VI (figure 4).

\section{Discussion}

Abnormal growth is a frequent finding in MPS patients. In particular in patients with MPS VI, normal growth is evident until 1.5 years of age and is then followed by growth stunting (-2 to -3 SD at 3.5 and 9 years, respectively).[18] Clinical trials with ERT have shown a slight improvement in growth rate (height), which is not statistically significant when compared to patients who are not on treatment.[19] An analysis of the patient's growth chart shows evidence of persistently low height for age (z-score<-2SD) a z-score measurement (-4.15) consistent with the mean reported by Quartel et al. [20] and Hsiang-Yu lin et al. [21] for untreated patients with MPS VI. This is consistent with the limited effect on growth found in Italian and Taiwanese patient cohorts treated with ERT. $[16,19]$ As shown in Figure 2, a progressive increase in weight (z-score +1.63 to +2.4 ) and BMI (obesity ranges) was documented. These findings prompted probing into eating habits and physical activities, revealing a hypercaloric diet and sedentarism, the latter due in part to challenges with physical activity secondary to the disease. This explains patient obesity, although there is no evidence of metabolic involvement.

Among patients with MPS VI, 96\% have cardiac compromise. During follow-up, the patient was diagnosed with mild aortic, mitral and tricuspid regurgitation. The cardiac parameters showed slow progression, which is consistent with reports from clinical trials with ERT, with no evidence of regression of findings but rather a slow, stable course.[13]Moreover, the patient has preserved lung function with no evident progression of the disease.

One of the most striking findings in this patient was the stabilization of urinary GAG levels. Measured levels support functional improvement with the treatment both from the pharmacodynamic as well as the biochemical standpoints, supporting stabilization of disease progression.[13,16]

Disease stabilization and subsequent prevention of GAG accumulation has resulted in a stable cardiac and pulmonary course, as well as improvement of joint pain, fine motor skills, speech and motor skills, enabling the child to continue in school, with adequate socialization. These are relevant outcomes resulting from the use of ERT.

During the follow-up period in clinical trials carried out in developed countries, patients on ERT are shown to have a high rate of adherence to treatment (94.6\%). However, these data do not reflect what happens 
in real life in Latin American countries where, despite the unavailability of ERT adherence statistics, it is estimated that compliance with treatment is lower. [13] In this patient, even in the face of challenges to ensure adequate follow-up, treatment was discontinued only in rare occasions because, as a beneficiary of special insurance coverage, the patient has had access to treatment and home infusions, with ensured adherence.

One of the limitations of this case report was the inability to ensure regular patient follow-up through office visits and regular testing as planned. However, the patient was followed in terms of clinical growth measurements, ophthalmological assessment, cardiovascular, neurological and endocrine function, showing limitation of disease progression and absence of drug-related adverse events.

\section{Conclusions}

Case report of a patient who has remained on enzyme replacement therapy for more than 6 years, with adequate adherence to the pharmacological treatment and no adverse reactions. GAG levels in the urine have remained stable. The course of the disease has been slow in terms of cardiac and pulmonary involvement, while observed improvements in motor skills and pain control have enabled the patient to continue in school. These findings support the long-term benefits of slowing the progression of the disease with galsulfase-based ERT as an option to modify the natural history of the disease and the quality of life in patients with MPS VI.

\section{Bibliographic References:}

[1] Neufeld EF, Muenzer, J. The mucopolysaccharidoses. Metab. Mol. Bases Inherit. Dis. , New York, NY: McGraw Hill; 2001;3421-3452.

[2] Giugliani R, Harmatz P, Wraith JE. Management guidelines for mucopolysaccharidosis VI. Pediatrics 2007. doi:10.1542/peds.2006-2184.

[3] Jurecka A, Golda A, Opoka-Winiarska V, Piotrowska E, Tylki-Szymańska A. Mucopolysaccharidosis Type VI (Maroteaux-Lamy syndrome) with a predominantly cardiac phenotype. Mol Genet Metab2011. doi:10.1016/j.ymgme.2011.08.024.

[4] Meikle P, Hopwood J, Clague A, Carey W. La prevalencia de los trastornos de almacenamiento lisosomal. J Am Med Assoc1999;281:249-254.

[5] Tomanin R, Karageorgos L, Zanetti A, Al-Sayed M, Bailey M, Miller N, et al . Mucopolysaccharidosis type VI (MPS VI) and molecular analysis: Review and classification of published variants in the ARSB gene. Hum Mutat 2018;39:1788-1802. doi:10.1002/humu.23613.

[6] Silipo A, Zhang Z, Cañada FJ, Molinaro A, Linhardt RJ, Jiménez-Barbero J. Conformational analysis of a dermatan sulfate-derived tetrasaccharide by NMR, molecular modeling, and residual dipolar couplings. ChemBioChem 2008. doi:10.1002/cbic.200700400.

[7] Simonaro CM, Haskins ME, Schuchman EH. Articular chondrocytes from animals with a dermatan sulfate storage disease undergo a high rate of apoptosis and release nitric oxide and inflammatory cytokines: A possible mechanism underlying degenerative joint disease in the mucopolysaccharidoses. Lab Investig 2001. doi:10.1038/labinvest.3780345.

[8] Simonaro CM, D'Angelo M, Haskins ME, Schuchman EH. Joint and bone disease in mucopolysaccharidoses VI and VII: Identification of new therapeutic targets and BioMarkers using animal models. Pediatr Res 2005. doi:10.1203/01.PDR.0000156510.96253.5A.

[9] Swiedler SJ, Beck M, Bajbouj M, Giugliani R, Schwartz I, Harmatz P, et al . Threshold effect of urinary glycosaminoglycans and the walk test as indicators of disease progression in a survey of subjects with Mucopolysaccharidosis VI (Maroteaux-Lamy syndrome). Am J Med Genet 2005. doi:10.1002/ajmg.a.30579. 
[10] Valayannopoulos V, Nicely H, Harmatz P, Turbeville S. Mucopolysaccharidosis VI. Orphanet J Rare Dis 2010. doi:10.1186/1750-1172-5-5.

[11] Wood TC, Harvey K, Beck M, Burin MG, Chien YH, Church HJ, et al . Diagnosing mucopolysaccharidosis IVA. J Inherit Metab Dis 2013. doi:10.1007/s10545-013-9587-1.

[12] Giugliani R, Gutierrez Carvalho C, Herber S, Lapagesse de Camargo Pinto L. Recent Advances in Treatment Approaches of Mucopolysaccharidosis VI. Curr Pharm Biotechnol 2011. doi:10.2174/138920111795542688.

[13] Giugliani R, Lampe C, Guffon N, Ketteridge D, Leão-Teles E, Wraith JE, et al . Natural history and galsulfase treatment in mucopolysaccharidosis VI (MPS VI, Maroteaux-Lamy syndrome)-10-year followup of patients who previously participated in an MPS VI survey study. Am J Med Genet Part A 2014. doi:10.1002/ajmg.a.36584.

[14] Akyol MU, Alden TD, Amartino H, Ashworth J, Belani K, Berger KI, et al . Recommendations for the management of MPS IVA: Systematic evidence and consensus-based guidance. Orphanet J Rare Dis 2019;14:1-21. doi:10.1186/s13023-019-1074-9.

[15] Harmatz P, Giugliani R, Ida IV, Guffon N, Teles EL, Miranda MCS, et al . Long-term follow-up of endurance and safety outcomes during enzyme replacement therapy for mucopolysaccharidosis VI: Final results of three clinical studies of recombinant human N-acetylgalactosamine 4-sulfatase. Mol Genet Metab 2008. doi:10.1016/j.ymgme.2008.04.001.

[16] Lin HY, Chen MR, Chuang CK, Chen CP, Lin DS, Chien YH, et al . Enzyme replacement therapy for mucopolysaccharidosis VI-experience in Taiwan. J Inherit Metab Dis 2010. doi:10.1007/s10545-010-9212-5.

[17] Lin HY, Chuang CK, Wang CH, Chien YH, Wang YM, Tsai FJ,et al . Long-term galsulfase enzyme replacement therapy in Taiwanese mucopolysaccharidosis VI patients: A case series. Mol Genet Metab Reports 2016. doi:10.1016/j.ymgmr.2016.04.003.

[18] Guffon N, Journeau P, Brassier A, Leger J, Chevallier B. Growth impairment and limited range of joint motion in children should raise suspicion of an attenuated form of mucopolysaccharidosis: expert opinion. Eur J Pediatr 2019;178:593-603. doi:10.1007/s00431-019-03330-x.

[19] Scarpa M, Barone R, Fiumara A, Astarita L, Parenti G, Rampazzo A, et al . Mucopolysaccharidosis VI: The Italian experience.Eur J Pediatr 2009. doi:10.1007/s00431-008-0910-z.

[20] Quartel A, Harmatz PR, Lampe C, Guffon N, Ketteridge D, Leão-Teles E, et al . Long-Term Galsulfase Treatment Associated With Improved Survival of Patients With Mucopolysaccharidosis VI (Maroteaux-Lamy Syndrome). J Inborn Errors Metab Screen2018;6:232640981875580. doi:10.1177/2326409818755800.

[21] Lin HY, Lee CL, Chiu PC, Niu DM, Tsai FJ, Hwu WL, et a l. Relationships among height, weight, body mass index, and age in taiwanese children with different types of mucopolysaccharidoses.Diagnostics 2019;9:1-11. doi:10.3390/diagnostics9040148.

[22] Giugliani R, Lampe C, Guffon N, Ketteridge D, Leão-Teles E, Wraith JE, et al . Natural History and Galsulfase Treatment in Mucopolysaccharidosis VI (MPS VI, Maroteaux-Lamy Syndrome) - 10 Year Follow-up of Patients Who Previously Participated in an MPS VI Survey Study Roberto. Am J Med Genet A 2014;164:1953-1964. doi:10.1002/ajmg.a.36584.Natural.

\section{Images:}

Figure 1: Patient's physical appearance 


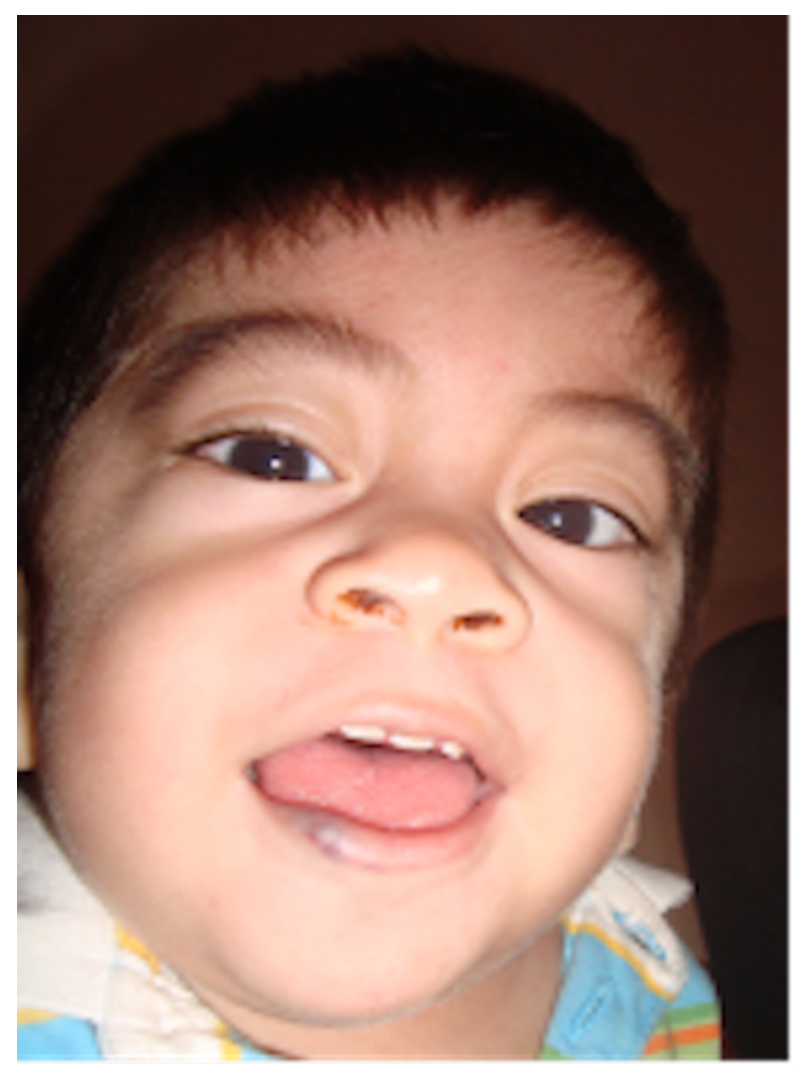

One-year-old patient showing evidence of coarse facies, prominent forehead, thick hair, bushy eyebrows, bulging eyes, broad nasal base, depressed nasal bridge and macroglossia.

Figure 2: Clinical follow-up: 


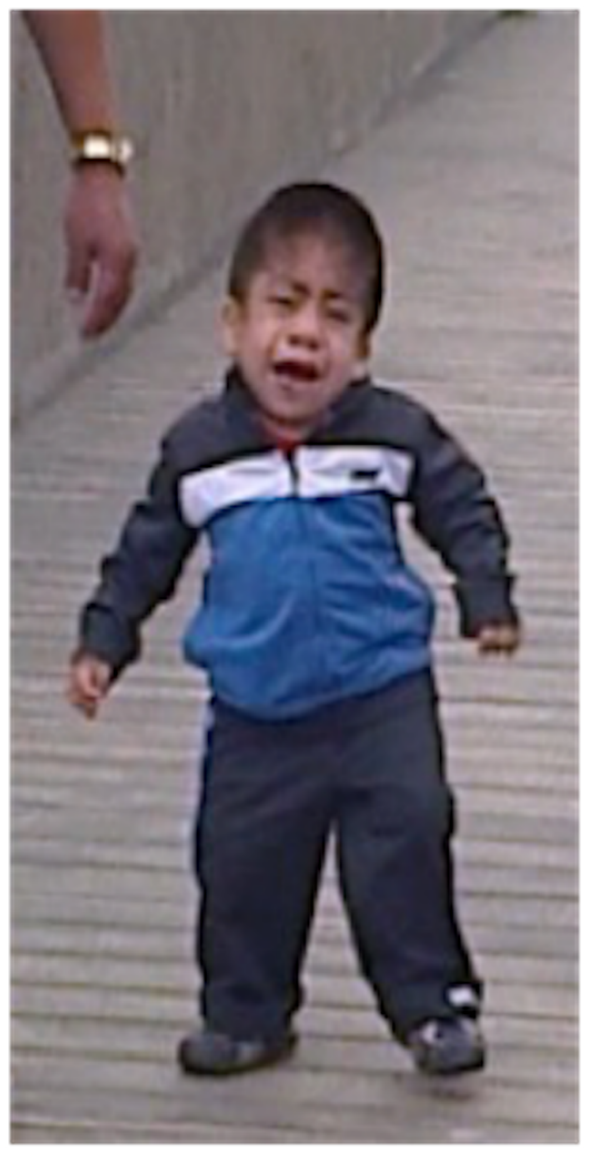

Patient at 3 years and 6 months of age, showing evidence of the facial features described above associated with genu valgum, claw hands and stiffness.

Figure 3: Six-year follow-up of weight, height and BMI:

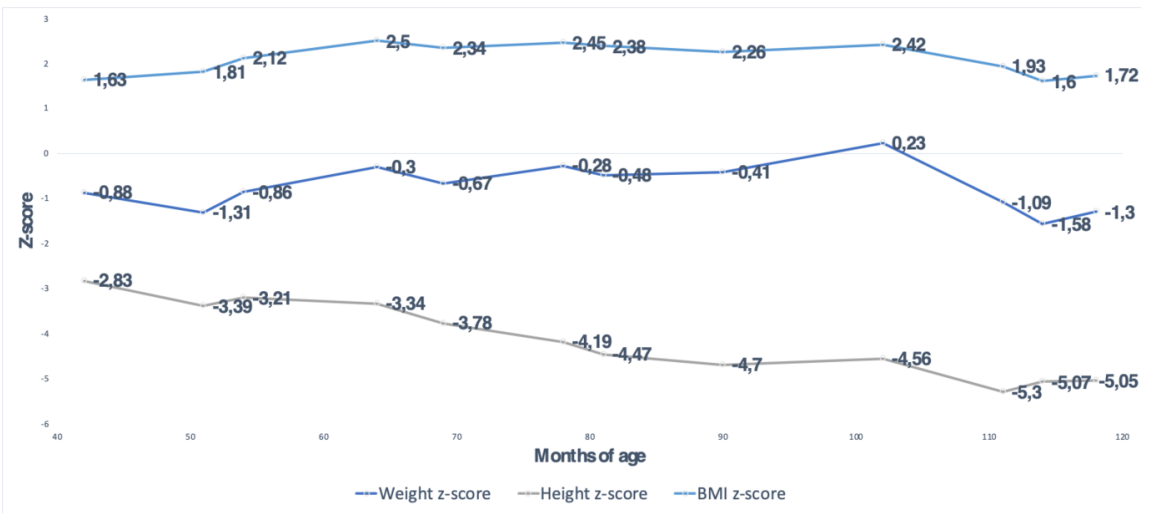


Z-score for weight, height and BMI during patient follow-up.

Figure 4: Clinical follow-up at 9 years 


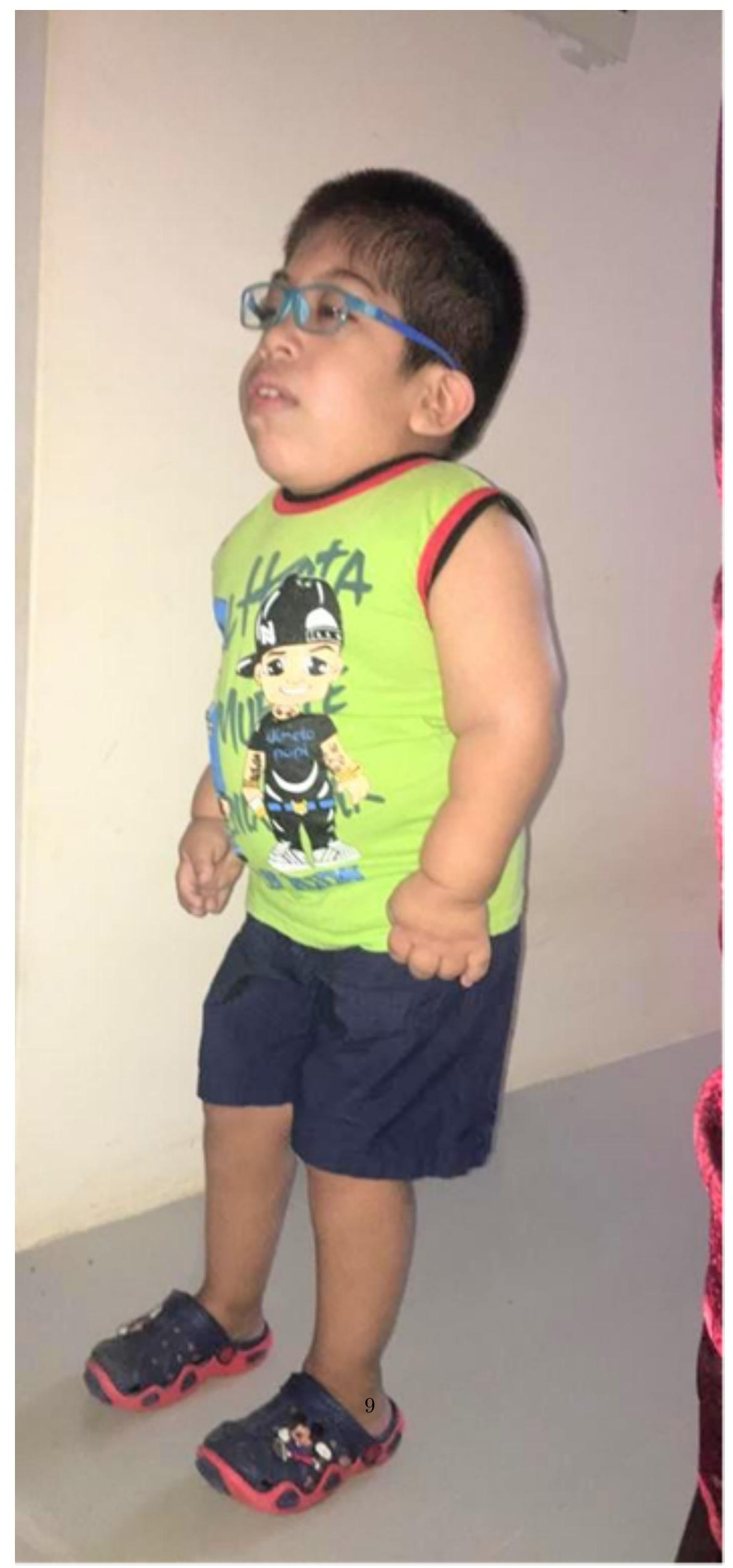


Patient at 9 years of age, showing evidence of the facial features described above associated with lumbar spine deformation and claw hands.

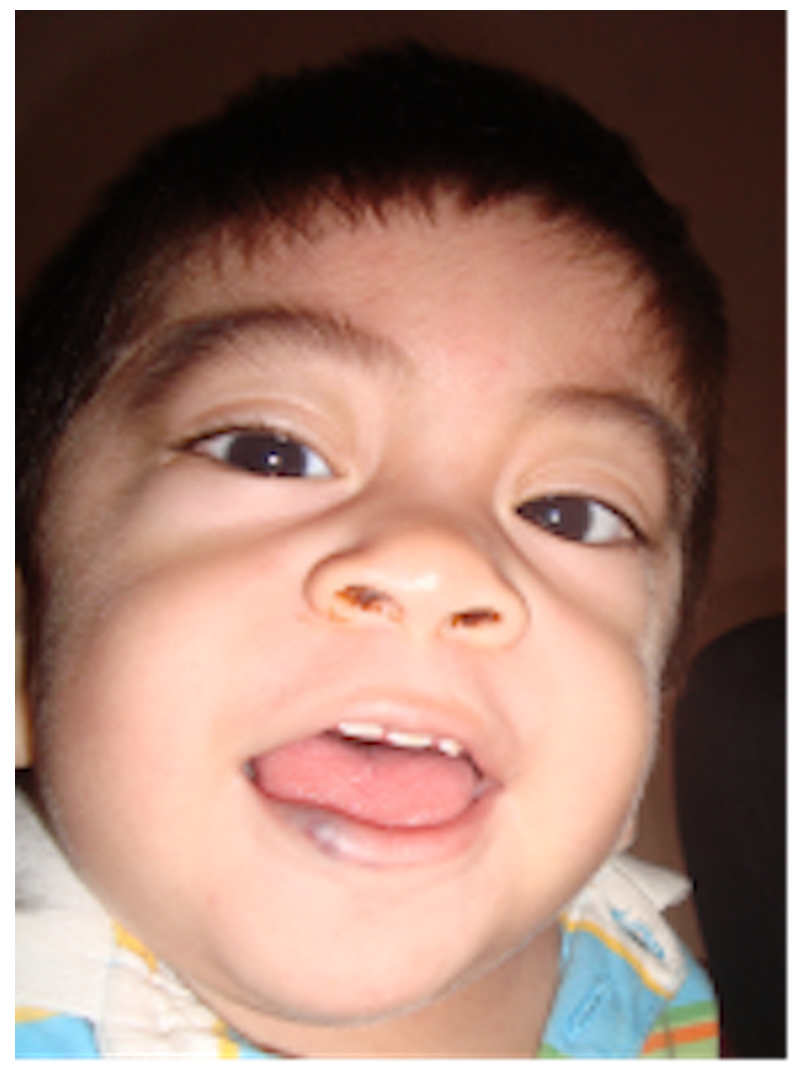



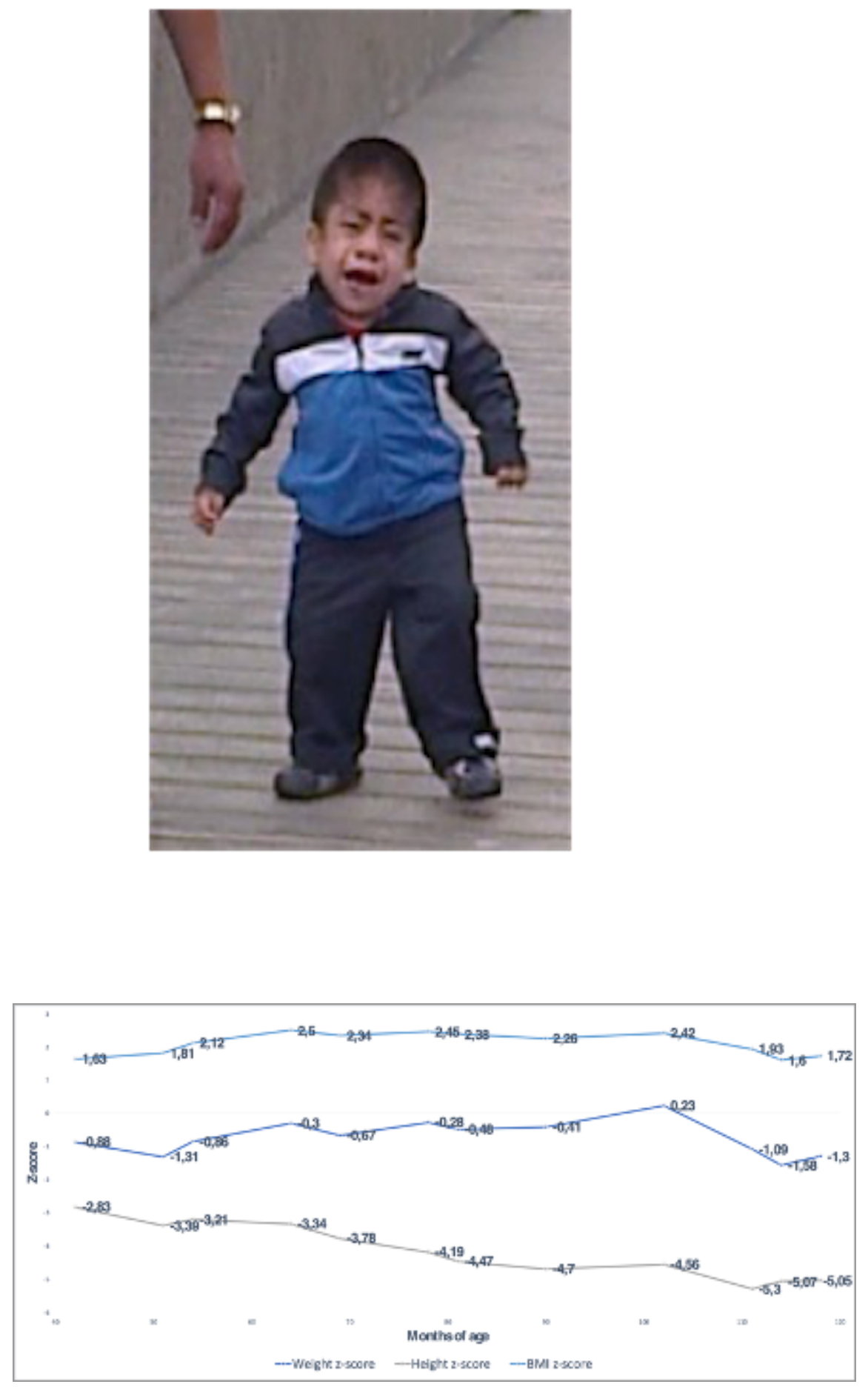


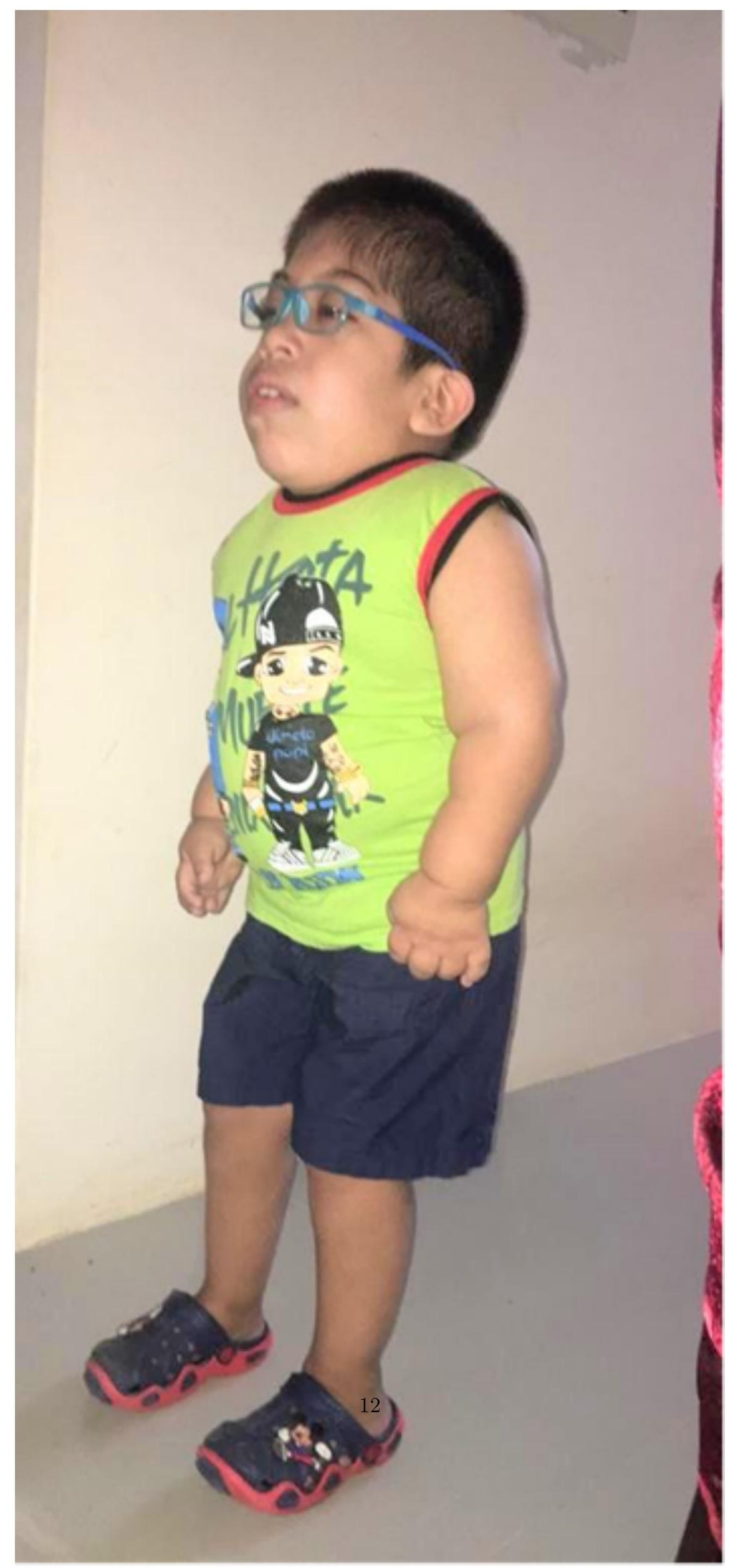

